\title{
Effects of zinc and a-linolenic acid supplementation on glycemia and lipidemia in women with type 2 diabetes mellitus: a randomized, double-blind, placebo-controlled trial
}

\author{
Meika Foster ${ }^{1}$, Peter Petocz ${ }^{2}$, lan D Caterson ${ }^{1,3}$ and Samir Samman ${ }^{1 *}$ \\ *Correspondence: samir.samman@sydney.edu.au \\ 'Discipline of Nutrition and Metabolism, School of Molecular Bioscience, University of Sydney, NSW 2006 Australia. \\ ${ }^{2}$ Department of Statistics, Macquarie University, NSW 2109 Australia. \\ ${ }^{3}$ Boden Institute of Obesity, Nutrition, Exercise \& Eating Disorders, University of Sydney, NSW 2006, Australia.
}

\begin{abstract}
Background: Nutritional supplements are used commonly by people with type 2 diabetes mellitus (T2DM). We aimed to investigate the effects of zinc and $\alpha$-linolenic acid (ALA) supplementation on markers of glycemia (glucose, HbA1c, insulin) and lipid levels (total cholesterol (TC), high density lipoprotein (HDL) cholesterol, low density lipoprotein (LDL) cholesterol, and triglycerides) in T2DM.

Methods: A randomized, double-blind, placebo-controlled, trial in postmenopausal women with T2DM. Participants received zinc ( $40 \mathrm{mg} / \mathrm{d})$ and/or ALA ( $2 \mathrm{~g} / \mathrm{d}$ flaxseed oil) for 12 weeks.

Results: In participants supplemented with zinc, the differences between initial (week 0) and final (week 12) HDL cholesterol levels and the TC:HDL ratio were marginally significant $(-0.1 \pm 0.04 \mathrm{mmol} / \mathrm{L}$ and $+0.1 \pm 0.1$, respectively; $P=0.04)$. An inverse relationship $(r=-0.59, P=0.04)$ between the changes in HDL cholesterol and HbAlc after 12 weeks was observed in the group supplemented with zinc. No significant effects of ALA treatment on glycemia or lipidemia were observed.w

Conclusions: In contrast to many studies, the participants in the present trial represent a population with medicallycontrolled T2DM and plasma zinc concentrations within the normal range. The effects of zinc on the lipid profile are similar to those reported in healthy populations, suggesting that medications commonly prescribed in the first-line treatment of T2DM may mask metabolic responses to zinc.
\end{abstract}

Key words: Nutrition, zinc, omega-3, postmenopausal women, lipids, glucose, diabetes

\section{Introduction}

Diabetes mellitus (DM) is a global public health problem. In a conservative estimate, the total number of people with DM is projected to rise from 171 million in 2000 to 366 million in 2030 [1], with T2DM being the most common form of the disease. Although the mechanisms that result in T2DM are complex and as yet not fully understood, some studies suggest that supplementation with zinc may modulate T2DM characteristics, including dyslipidemia, chronic hyperglycemia, and insulin resistance $[2,3]$. Omega-3 polyunsaturated fatty acids ( $n-3$ PUFA) also have been reported to have beneficial effects on glycemia and lipidemia $[4,5]$, suggesting that the potentially beneficial effects of zinc in T2DM may be augmented by concurrent n-3 PUFA supplementation.

Dyslipidemia is a common feature of the T2DM pathology. The major changes in lipid profile in T2DM are an increase in triglycerides, a reduction in $\mathrm{HDL}$ cholesterol, and the increased appearance of small, dense LDL particles, which are particularly susceptible to oxidative modification [6]. Zinc supplementation in T2DM has been reported to decrease total cholesterol and triglyceride concentrations [7]. In our recent meta-analysis, zinc supplementation was associated with an increase in $\mathrm{HDL}$ cholesterol concentrations in individuals with T2DM [8]. The mechanism may involve insulin, which has been proposed as an independent predictor of plasma HDL and triglyceride concentrations [9].

Zinc supplementation has been reported to improve glycemic control in humans with T2DM [10-12]. Chronic hyperglycemia is consequent upon the decreased secretion or action of insulin, which may explain some of the effects of zinc on glucose homeostasis. Zinc functions in the synthesis, storage, secretion, and action of insulin $[13,14]$. In addition, recent evidence has demonstrated a role for zinc in the induction of the PI3K/Akt cascade [15], a major mediator of insulin signaling.

The effects of long-chain n-3 PUFA supplementation on glycemia and lipidemiain T2DM have been extensively studied. The most consistent effect of supplementation 
with eicosapentaenoic acid (EPA) and docosahexaenoic acid (DHA) on the lipid profile is a decrease in serum triglyceride concentrations in participants with and without hypertriglyceridemia [5,16-17]. In contrast, randomised controlled trials have shown adverse effects of supplementation with long-chain n-3 PUFA on glycemic control and insulin sensitivity [18-21]. Consistent with these findings, a large prospective study recently reported that intakes of marine but not plant-based n-3 PUFA were associated with increased risk of T2DM in women [22]. The effects of non-marine sources of $n-3$ PUFA on metabolic parameters in T2DM are not clearly defined. Supplementation with alpha-linolenic acid (ALA) from flaxseed oil was not shown to lower triglyceride concentrations in one study in T2DM [23], although it has been shown to do so in a healthy population [24]. The effects of zinc and n-3 PUFA, administered jointly, on hyperglycemia and dyslipidemia in DM are presently unknown.

The present trial was designed to follow up the finding in our meta-analysis of an association between zinc supplementation and an increase in HDL cholesterol concentrations in T2DM [8] and to explore the effects of concurrent zinc and n-3 PUFA supplementation in this population. Specifically, it aims to investigate the effects of zinc, with and without ALA supplementation, on HDL cholesterol concentrations in postmenopausal women with T2DM, as well as on other lipid levels (total cholesterol, LDL cholesterol, triglycerides) and markers of glycemia (glucose, $\mathrm{HbA1c}$, insulin). A second aim is to explore the relationships among plasma zinc concentrations, glycemic markers, and lipid outcomes.

\section{Materials and Methods Study population}

Women with T2DM were contacted and invited to participate in the trial by use of established mailing lists of DM organisations. In addition, the study was advertised in local Sydney newspapers, through medical and dietetic practices, and around the University of Sydney campus. Women who indicated an interest in enrolling in the study were sent detailed information about the trial and an initial questionnaire to complete and return for the determination of eligibility.

The primary inclusion criteria required participants to be postmenopausal women (no menses for $>12 \mathrm{mo}$ ) with T2DM (controlled either by diet and lifestyle or oral hypoglycemic medication prescribed within the previous 7 y) and a normal Glomerular Filtration Rate and microalbumin/creatine ratio. The requirement that participants be postmenopausal was intended to reduce confounding by estrogen fluctuations, which may influence zinc homeostasis [25]. Exclusion criteria were: diagnosis with any current major illness (e.g. cancer, coronary heart disease) other than DM; the use of insulin; tobacco use; and the taking of prescription medications known to interact with zinc (e.g. medications for depression). The use of first line preventative medications for the treatment of diabetic comorbidities (such as HMGCoA reductase inhibitors (statins) for hypercholesterolemia and ACE inhibitors for hypertension) was not an exclusion criterion. Women on hormone replacement therapies were excluded, with the exception of thyroxine which was permitted (pursuant to medical advice) provided the dose was stable over more than 6 months. Potential participants were advised that they would be expected to refrain from giving blood donations and from the use of all nutritional supplements (excluding trial supplements) in the 6 weeks prior to the trial and throughout the trial period.

The Human Research Ethics Committee of the University of Sydney approved the study protocol and all participants provided written informed consent. The protocol was registered at www.clinicaltrials.gov (NCT01505803).

\section{Randomization and intervention}

The study was a randomized, double-blind, placebocontrolled trial conducted over 12 weeks. Participants, the trial coordinator and personnel, and outcome investigators were blinded to treatment allocation. Eligible participants were randomized into four equal groups according to a computer-generated random-number sequence to receive a total of $40 \mathrm{mg} / \mathrm{d}$ elemental zinc ('Zn group'), $2000 \mathrm{mg} / \mathrm{d}$ flaxseed oil ('ALA group'), both zinc and flaxseed oil (' $Z n+A L A$ group'), or placebo. The zinc dose of $40 \mathrm{mg} / \mathrm{d}$ was selected as it represents the upper level of recommended zinc intake [26] and is similar to the median zinc dose $(50 \mathrm{mg} / \mathrm{d})$ used in T2DM supplementation trials in our meta-analysis investigating the effects of zinc on plasma lipoprotein cholesterol concentrations in humans [8]. The adequate intake of ALA in adult women is defined as $800 \mathrm{mg} / \mathrm{d}$ [26]; $2000 \mathrm{mg}$ flaxseed oil provides $1200 \mathrm{mg}$ ALA. Study treatment was given as four capsules to be taken daily. In order to minimize the potential for side effects and enhance absorption in those receiving zinc [27-28], participants were instructed to consume the trial supplements in two equal parts (one part in the morning, one part in the evening, before food). Zinc and flaxseed oil capsules differed in appearance and so each had a matching placebo. Zinc active and placebo capsules were prepared by a compounding pharmacist (Health Information Pharmacy, Balmain, Sydney, Australia). Each zinc active capsule comprised a clear shell containing $20 \mathrm{mg}$ of elemental zinc (in the form of zinc sulphate monohydrate; Blackmores Ltd, Sydney, Australia) and cellulose filler as required, resulting in a capsule of white appearance; zinc placebo capsules contained cellulose and were identical in appearance to their active counterparts. ALA active capsules (Blackmores Ltd, Sydney, Australia) each comprised an opaque black shell containing $1000 \mathrm{mg}$ of flaxseed oil (equivalent to $600 \mathrm{mg} \mathrm{ALA).} \mathrm{ALA} \mathrm{placebo}$ capsules (Catalent Australia Pty Ltd, Victoria, Australia) 
utilized an identical opaque black shell filled with 1000 $\mathrm{mg}$ of olive oil. The fatty acid composition of the olive oil was: palmitic acid $9.7 \%$; stearic acid $2.5 \%$; oleic acid $74.5 \%$; linoleic acid 11.4\%; ALA $0.7 \%$. The capsules were tasteless and the organoleptic properties of the oils were unable to be distinguished. Quality control was conducted at the beginning of the study to verify supplement content. Capsules were packaged in 4-weekly lots (60 capsules), labeled with coded assignment numbers, and dispensed at baseline, week 4 , and week 8 .

Compliance with the intervention was assessed by capsule counting at weeks 4,8 , and 12 . A questionnaire was administered at each follow-up appointment to ascertain self-reported compliance and to determine whether participants were experiencing any positive or negative effects that they attributed to the supplements.In addition, participants were questioned at baseline and at each time point to ensure that no nutritional supplements (other than trial supplements) were consumed in the 6 weeks prior to the trial and throughout the trial period.

\section{Collection of descriptive information}

Height (to $\pm 0.1 \mathrm{~cm}$ ) was measured at baseline with a wall-mounted stadiometer and body weight (to \pm 100 g) was measured with an electronic calibrated scale at each appointment for the determination of BMI $\left(\mathrm{kg} / \mathrm{m}^{2}\right)$. Data on age, change in weight over the 3 month period preceding the study, time since DM diagnosis and current management strategies, family history of DM, and usual alcohol consumption were self-reported at baseline.

\section{Collection of dietary information}

Participants completed two non-sequential estimated food records (one weekday record and one weekend day record) in the 7 day period prior to their participation in the study for the assessment of baseline dietary intake. This process was repeated in the 7 day period prior to the final appointment for the assessment of week 12 dietary intake. Participants were instructed as to the appropriate days on which to record their food intake and provided with food record templates and detailed guidelines on how to complete them. The research dietitian checked each record in the presence of the participant for consistency and completeness. Food records were analysed (Foodworks, Professional Edition 2009; Xyris Software, QLD, Australia) for the determination of energy, protein, fat (total, saturated (SFA), monounsaturated (MUFA) and polyunsaturated (PUFA) fatty acids), carbohydrate, dietary fibre, alcohol and zinc intakes. The results from the two food records at each time point were averaged to obtain the final baseline and week 12 nutrient intake values.

\section{Blood collection}

Venous blood samples were collected from participants at each time point after an overnight fast of at least 10 hours.
Serum gel tubes were used for cholesterol, triglycerides, glucose, and insulin analyses, EDTA tubes for analysis of $\mathrm{HbA1c}$, and trace metal tubes (Becton Dickinson) for plasma zinc analysis. Blood collection procedures were in accordance with the guidelines of the International Zinc Nutrition Consultative Group [29].

\section{Cholesterol and triglycerides}

Total cholesterol, HDL-cholesterol, and triglycerides were measured on a Modular PPE auto-analyzer (Roche Diagnostics, Basel, Switzerland) using enzymatic colorimetric methods [30-32]. The measuring range of each assay was $0.08-20.7$ $\mathrm{mmol} / \mathrm{L}, 0.08-3.10 \mathrm{mmol} / \mathrm{L}$, and $0.05-11.3 \mathrm{mmol} / \mathrm{L}$, respectively. The inter- and intra-assay co-efficients of variation were $<2.1 \%$ for total cholesterol and $\mathrm{HDL}$-cholesterol and $<3 \%$ for triglycerides. LDL cholesterol was estimated using the SI version [33] of the Friedewaldequation [34].

\section{Glucose, insulin, HOMA-IR, HbAlc}

Glucose was measured by glucose hexokinase UV method [35] using the Gluco-quant reagent kit adapted for a Modular PPE auto-analyzer (Roche Diagnostics, Basel, Switzerland), according to the manufacturer's instructions. The inter- and intra-assay coefficients of variation for glucose were $<2.8 \%$, with a measuring range of $0.11-41.6$ $\mathrm{mmol} / \mathrm{L}$. Insulin was determined using a chemiluminescent microparticle immunoassay [36] on an Architect i2000SR Analyzer (Abbott Laboratories, Abbott Park, IL, USA). The measurement range for the insulin assay was $1.0 \mu \mathrm{U} /$ $\mathrm{mL}-300.0 \mu \mathrm{U} / \mathrm{mL}$, with inter- and intra-assay coefficients of variation $<2.1 \%$. Insulin resistance was estimated using the homeostasis model assessment (HOMA-IR) calculation: fasting glucose $(\mathrm{mmol} / \mathrm{L}) \times$ fasting insulin $(\mathrm{mU} / \mathrm{L}) / 22.5$ [37]; insulin conversion factor, $1 \mathrm{mU} / \mathrm{L}=6.00 \mathrm{pmol} / \mathrm{L}$ insulin. Hemoglobin A1c (HbA1c) was assayed using ion-exchange high performance liquid chromatography (HPLC) on a Variant II analyzer equipped with the Variant II NU Program (Bio-Rad Laboratories, Hercules, CA, USA), according to the manufacturer's protocol. All samples returned results within the reportable linear range (3.1-18.5\%); within run and between run coefficients of variability were < $1.7 \%$. The equation describing the conversion of HBA1c to SI Units is: IFCC-HbA1c $(\mathrm{mmol} / \mathrm{mol})=[$ DCCT-HbA1c (\%) - 2.15] x 10.929.

\section{Plasma zinc}

Plasma from trace metal tubes was prepared by centrifugation at $4^{\circ} \mathrm{C}$ for $10 \mathrm{~min}$ at $3000 \mathrm{rpm}$ and stored at $-80^{\circ} \mathrm{C}$ until further analysis. Plasma zinc was determined using inductively coupled plasma mass spectrometry (Agilent 7500ce ICPMS, Santa Clara, CA). Samples were diluted (1:40) in ammonium EDTA using rhodium as an internal standard and measured against a matrix-matched standard curve prepared in the same dilution. Samples were analyzed in duplicate in a single batch (coefficient of variation $<5 \%$ ) 


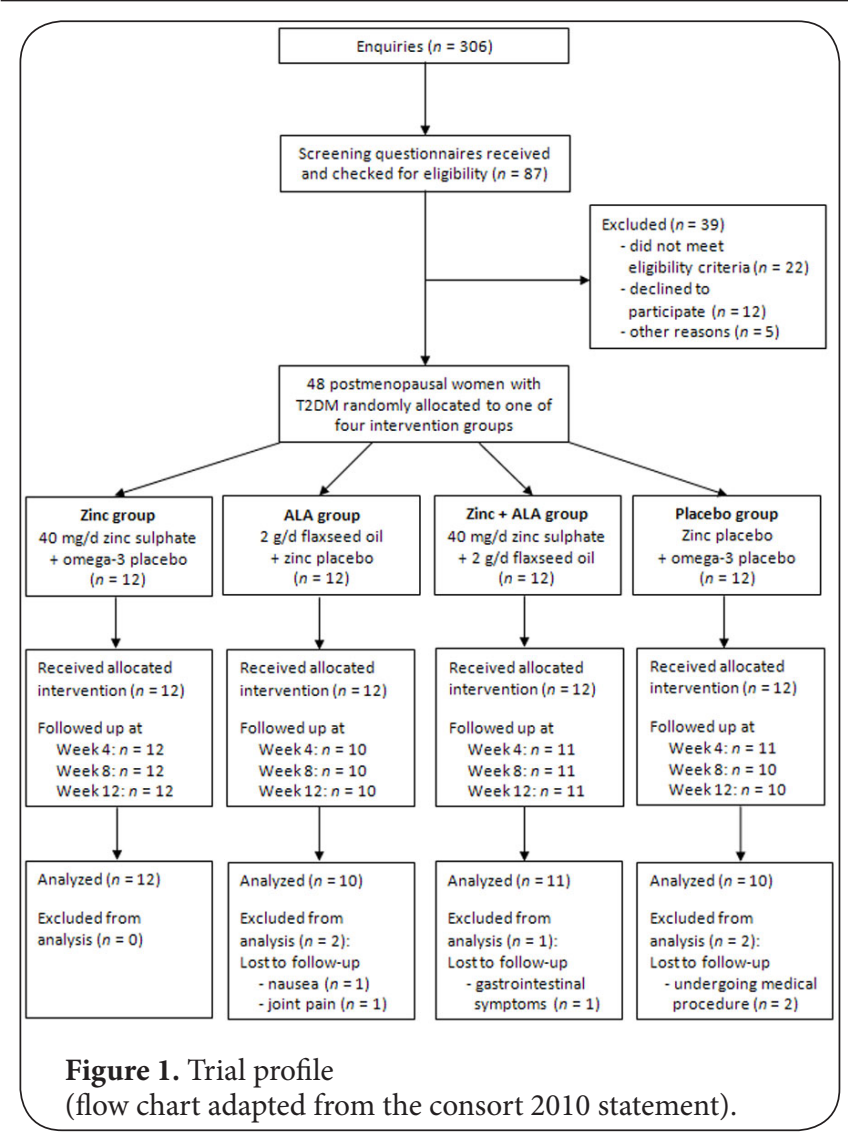

and appropriate quality control sera were utilized (Trace Element Control Serum, UTAK Laboratories, Inc, Valencia, CA).

\section{Statistical methods}

The planned enrollment of 48 participants ( 10 participants per intervention group and allowing for an attrition rate of $20 \%$ ) was projected to detect a $10 \%$ increase in the serum $\mathrm{HDL}$ concentration with $80 \%$ power and a standard deviation of $6.4 \%$ using a test with $5 \%$ level of significance. Sample size projections were based on the results of our previous meta-analysis investigating the effects of zinc on plasma lipoprotein cholesterol concentrations in humans, which demonstrated an increase in HDL cholesterol in T2DM [8].

Participant characteristics are described using mean \pm SD for descriptive variables (age, BMI, time since DM diagnosis), proportions for categorical data (use of medications), and mean \pm s.e. for estimates (dietary intakes, biochemical measures). Differences in group means at baseline were investigated using ANOVA for continuous data and the Pearson chi-square test for categorical variables. Repeated measures ANOVA of each factor by treatment group was undertaken, with a Greenhouse-Geisser adjustment for asphericity. In secondary analyses, the significance of the change in the mean value for each variable (week 12 - baseline) was calculated within each group using paired student t-tests. Bivariate correlations between biochemical measures were calculated using the Pearson correlation coefficient.

Statistical analyses were carried out using SPSS (PASW) version 18 (SPSS Inc,www.spss.com). The assumptions of normality and homoscedasticity of residuals were satisfied in the analyses. A value of $P<0.01$ was taken to designate statistical significance, with $0.01 \leq P<0.05$ indicating marginal significance. We took a conservative approach and interpreted $P<0.05$ as statistically marginal due to the large number of test results under investigation.

\section{Results}

Figure 1 shows the trial profile. Of 306 potential participants who indicated interest in enrolling in the study, 87 returned eligibility questionnaires. Twenty-two women did not meet the eligibility criteria, 12 women declined to participate despite being eligible, and 5 others withdrew their interest due to unexpected caregiver responsibilities or other family-related reasons. Forty-eight women were enrolled in the trial.

Forty-three participants completed the trial and were included in the statistical analysis. A 'complete case' analysis was preferred to a strict intention-to-treat approach as only baseline data were available for four of the five participants lost to follow-up, making it difficult to justify the imputation of missing data for weeks 4,8 and 12 . The frequency and causes of participant withdrawal from the trial did not relate to any particular treatment.

The age and BMI of the 43 participants who completed the trial were $65.0 \pm 7.8 \mathrm{y}$ (mean $\pm \mathrm{SD}$ ) and $28.6 \pm 5.1 \mathrm{~kg} /$ $\mathrm{m}^{2}$,respectively. The average time since diagnosis of T2DM was $6.5 \pm 5.2$ y. Participants reported taking oral hypoglycaemic (63\%), lipid lowering (72\%), and other prescription medication (67\%). Three participants did not take any medication. There were no significant differences in the baseline characteristics (Table 1) or dietary intakes (Table 2) of participants after randomization into intervention groups, however the proportion of participants who reported taking oral hypoglycaemic agents tended to be lower in the ALA group $(P=0.07)$. Overall compliance with the interventions (based on capsule counting and participant self-reporting) was $94.1 \pm 5.6 \%$, with no significant differences between groups.

\section{Glycemic and lipidemic markers}

Serum concentrations of the glycemic and lipid measures in the four intervention groups at baseline were within their respective reference intervals, except for $\mathrm{HbA1c}$ which was above the normal range (Table 3). Using repeated measures analysis of treatment by group, no significant effects of zinc and ALA supplementation on serum concentrations of the glycemic and lipidemic markers were observed. The differences in the Zn group between initial (week 0) and final (week 12) HDL cholesterol levels and the TC:HDL ratio were marginally significant $(-0.1 \pm 0.04 \mathrm{mmol} / \mathrm{L}$ and $+0.1 \pm 0.1$, respectively; $P=0.04)$. In the placebo group, 
Foster et al. Journal of Diabetes Research \& Clinical Metabolism 2013,

http://www.hoajonline.com/journals/pdf/2050-0866-2-3.pdf

Table 1. Demographic characteristics at baseline of participants who completed the trial ${ }^{a}$.

\begin{tabular}{llllll}
\hline & $\begin{array}{l}\text { Zn } \\
(\mathbf{n}=12)\end{array}$ & $\begin{array}{l}\text { ALA } \\
(\mathbf{n = 1 0})\end{array}$ & $\begin{array}{l}\text { Zn + ALA } \\
(\mathbf{n = 1 1 )}\end{array}$ & $\begin{array}{l}\text { Placebo } \\
(\mathbf{n = 1 0})\end{array}$ & P-value \\
\hline Age (y) & $65.9 \pm 10.8$ & $66.2 \pm 8.4$ & $63.1 \pm 5.1$ & $64.6 \pm 5.8$ & 0.80 \\
& $(52.6-2.7)$ & $(51.8-76.8)$ & $(53.0-71.3)$ & $(58.5-78.0)$ & \\
BMI $\left(\mathrm{kg} / \mathrm{m}^{2}\right)$ & $26.0 \pm 4.9$ & $29.9 \pm 4.9$ & $30.0 \pm 4.9$ & $29.0 \pm 5.3$ & 0.20 \\
& $(19.0-34.8)$ & $(22.9-37.5)$ & $(24 .-37.7)$ & $(19.9-37.8)$ & \\
Time since DM diagnosis (y) & $7.7 \pm 5.9$ & $8.2 \pm 7.8$ & $5.1 \pm 2.8$ & $4.8 \pm 2.4$ & 0.33 \\
& $(1-18)$ & $(1-28)$ & $(2-10)$ & $(2-10)$ & \\
Use of medictions - $n(\%)^{\mathrm{b}}$ & & & & & \\
$\quad$ - oral hypoglycaemic & $10(83)$ & $3(30)$ & $7(64)$ & $7(70)$ & 0.07 \\
$\quad$ - lipid lowering & $9(75)$ & $8(80)$ & $7(64)$ & $7(70)$ & 0.86 \\
- other & $10(83)$ & $7(70)$ & $5(46)$ & $7(70)$ & 0.28 \\
\hline
\end{tabular}

${ }^{\mathrm{a}}$ Data are expressed as mean \pm SD (range) unless otherwise indicated; ${ }^{\mathrm{b}} \mathrm{P}$-value for proportions (Pearson Chi-Square).

Table 2. Average dietary intakes at baseline of participants who completed the trial ${ }^{\text {. }}$

\begin{tabular}{|c|c|c|c|c|c|}
\hline & $\begin{array}{c}\mathrm{Zn} \\
(\mathrm{n}=12)\end{array}$ & $\begin{array}{c}\text { ALA } \\
(\mathbf{n}=10)\end{array}$ & $\begin{array}{c}\mathrm{Zn}+\text { ALA } \\
(\mathrm{n}=\mathbf{1 1})\end{array}$ & $\begin{array}{l}\text { Placebo } \\
(\mathbf{n}=10)\end{array}$ & P-value \\
\hline Energy (MJ/d) & $\begin{array}{c}7.0 \pm 0.54 \\
(4.6-10.4)\end{array}$ & $\begin{array}{c}7.0 \pm 0.54 \\
(4.6-10.5)\end{array}$ & $\begin{array}{c}7.7 \pm 0.57 \\
(5.3-12.1)\end{array}$ & $\begin{array}{c}7.4 \pm 0.66 \\
(4.2-10.8)\end{array}$ & 0.77 \\
\hline Protein $(\mathrm{g} / \mathrm{d})$ & $\begin{array}{c}94.4 \pm 7.4 \\
(58.5-145.0)\end{array}$ & $\begin{array}{c}86.1 \pm 9.0 \\
(43.0-123.0)\end{array}$ & $\begin{array}{c}100.5 \pm 8.9 \\
(64.0-145.0)\end{array}$ & $\begin{array}{c}89.1 \pm 8.7 \\
(44.0-124.0)\end{array}$ & 0.65 \\
\hline Total fat $(\mathrm{g} / \mathrm{d})$ & $\begin{array}{c}57.7 \pm 7.8 \\
(21.5-125.0)\end{array}$ & $\begin{array}{c}60.1 \pm 6.0 \\
(37.5-91.5)\end{array}$ & $\begin{array}{c}64.3 \pm 8.6 \\
(34.5-132.0)\end{array}$ & $\begin{array}{c}62.2 \pm 5.7 \\
(34.0-88.5)\end{array}$ & 0.92 \\
\hline SFA & $\begin{array}{c}20.7 \pm 2.7 \\
(8.0-37.5)\end{array}$ & $\begin{array}{c}24.7 \pm 2.3 \\
(16.0-37.5)\end{array}$ & $\begin{array}{c}22.7 \pm 2.6 \\
(11.5-35.0)\end{array}$ & $\begin{array}{c}21.5 \pm 2.5 \\
(7.5-32.0)\end{array}$ & 0.71 \\
\hline PUFA & $\begin{array}{c}8.9 \pm 1.2 \\
(4.0-17.5)\end{array}$ & $\begin{array}{c}9.0 \pm 1.6 \\
(3.0-19.5)\end{array}$ & $\begin{array}{c}10.8 \pm 1.6 \\
(4.5-22.5)\end{array}$ & $\begin{array}{c}12.0 \pm 1.7 \\
(6.5-22.5)\end{array}$ & 0.43 \\
\hline MUFA & $\begin{array}{c}23.2 \pm 4.3 \\
(7.0-61.5)\end{array}$ & $\begin{array}{c}21.6 \pm 2.5 \\
(10.5-35.0)\end{array}$ & $\begin{array}{c}25.5 \pm 4.5 \\
(12.5-64.5)\end{array}$ & $\begin{array}{c}23.8 \pm 2.3 \\
(11.0-33.0)\end{array}$ & 0.91 \\
\hline Carbohydrate (g/d) & $\begin{array}{c}178.8 \pm 13.9 \\
(115.5-263.5)\end{array}$ & $\begin{array}{c}179.4 \pm 18.4 \\
(110.5-281.5)\end{array}$ & $\begin{array}{c}198.8 \pm 14.4 \\
(136.5-278.5)\end{array}$ & $\begin{array}{c}191.9 \pm 21.4 \\
(118.5-352.0)\end{array}$ & 0.80 \\
\hline Dietary Fibre (g/d) & $\begin{array}{c}27.4 \pm 2.6 \\
(14.5-44.5)\end{array}$ & $\begin{array}{c}23.1 \pm 3.0 \\
(9.0-38.5)\end{array}$ & $\begin{array}{c}31.9 \pm 4.5 \\
(15.0-66.0)\end{array}$ & $\begin{array}{c}27.6 \pm 3.9 \\
(15.0-54.0)\end{array}$ & 0.40 \\
\hline Alcohol (g/d) & $\begin{array}{c}0.83 \pm 0.58 \\
(0.0-6.0)\end{array}$ & $\begin{array}{c}4.1 \pm 2.9 \\
(0.0-29.5)\end{array}$ & $\begin{array}{c}2.0 \pm 1.1 \\
(0.0-10.5)\end{array}$ & $\begin{array}{c}3.7 \pm 2.9 \\
(0.0-28.5)\end{array}$ & 0.64 \\
\hline $\operatorname{Zinc}(\mathrm{mg} / \mathrm{d})$ & $\begin{array}{c}11.0 \pm 1.1 \\
(5.5-18.8)\end{array}$ & $\begin{array}{c}11.8 \pm 1.5 \\
(6.1-19.9)\end{array}$ & $\begin{array}{c}12.0 \pm 1.1 \\
(8.4-19.7)\end{array}$ & $\begin{array}{c}12.0 \pm 1.5 \\
(5.9-21.5)\end{array}$ & 0.93 \\
\hline
\end{tabular}

${ }^{\mathrm{a}}$ Data are expressed as mean \pm s.e. (range); SFA, saturated fatty acid; PUFA, polyunsaturated fatty acid; MUFA, monounsaturated fatty acid.

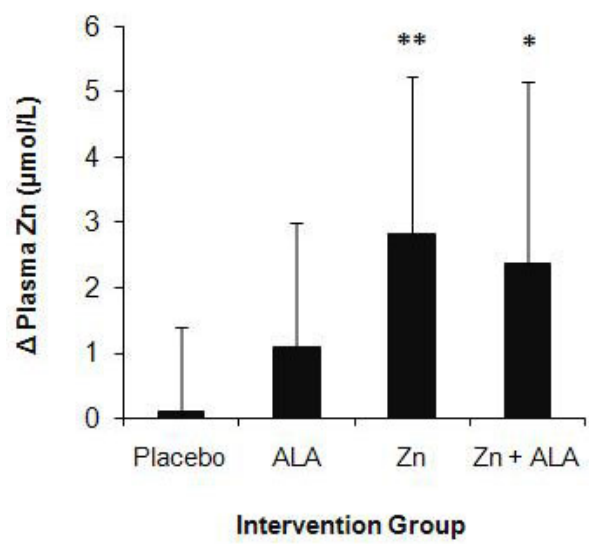

Figure 2. Change in plasma zinc concentration over 12 weeks (week 12 - baseline values) in each of the four intervention groups. ${ }^{\star} P<0.05 ;{ }^{*} P<0.01$. marginally significant decreases were noted in the placebo group for insulin and HOMA-IR $(P=0.02)$, as well as a trend $(P=0.06)$ towards a decrease in glucose concentrations over the four time points.

\section{Plasma zinc}

In all four groups, plasma zinc values were within the reference range $(10-18 \mu \mathrm{mol} / \mathrm{L})$. Repeated measures analysis by group identified a marginal $(P=0.056)$ effect of treatment on plasma zinc. In the $\mathrm{Zn}$ group, the difference in the plasma zinc concentration at week 12 compared to baseline was $+2.8 \mu \mathrm{mol} / \mathrm{L}(P=0.002)$; after $\mathrm{Zn}+\mathrm{ALA}$ supplementation the increase was $+2.4 \mu \mathrm{mol} / \mathrm{L}(P=0.019)$ (Figure 2).

\section{Relationships among biochemical measures}

A number of bivariate correlations were observed between 
Foster et al. Journal of Diabetes Research \& Clinical Metabolism 2013, http://www.hoajonline.com/journals/pdf/2050-0866-2-3.pdf

Table 3. Effects of zinc $(n=12)$, ALA $(n=10)$, and zinc + ALA $(n=11)$ interventions compared to placebo $(n=10)$ over time (weeks 4,8,12 compared to baseline) on serum measures of glycemia and lipidemia, and plasma zinc in participants who completed the trial ${ }^{\mathrm{a} b \mathrm{~b}}$.

\begin{tabular}{|c|c|c|c|c|c|c|c|}
\hline Group & $P(\mathrm{RM})^{\mathrm{c}}$ & Baseline & Week 4 & Week 8 & Week 12 & $\Delta^{\mathrm{d}}$ & $P^{\mathrm{e}}$ \\
\hline Glucose, random $(\mathrm{mmol} / \mathrm{L})$ & 0.18 & - & - & - & - & - & - \\
\hline $\mathrm{Zn}$ & & $6.8 \pm 0.5$ & $7.0 \pm 0.7$ & $7.1 \pm 0.6$ & $6.7 \pm 0.6$ & $-0.1 \pm 0.2$ & 0.65 \\
\hline ALA & & $7.3 \pm 0.6$ & $7.3 \pm 0.7$ & $7.0 \pm 0.7$ & $7.4 \pm 0.7$ & $0.1 \pm 0.3$ & 0.74 \\
\hline $\mathrm{Zn}+\mathrm{ALA}$ & & $6.8 \pm 0.5$ & $7.5 \pm 0.7$ & $7.1 \pm 0.6$ & $7.1 \pm 0.7$ & $0.3 \pm 0.3$ & 0.21 \\
\hline placebo & & $7.0 \pm 0.6$ & $7.4 \pm 0.7$ & $6.8 \pm 0.7$ & $6.6 \pm 0.7$ & $-0.4 \pm 0.3$ & 0.18 \\
\hline HbAlc $(\%)^{\mathrm{f}}$ & 0.24 & - & - & - & - & - & - \\
\hline $\mathrm{Zn}$ & & $6.6 \pm 0.3$ & $6.7 \pm 0.3$ & $6.8 \pm 0.3$ & $6.8 \pm 0.3$ & $0.1 \pm 0.1$ & 0.32 \\
\hline ALA & & $7.0 \pm 0.3$ & $6.9 \pm 0.3$ & $7.0 \pm 0.3$ & $7.0 \pm 0.3$ & $0.0 \pm 0.1$ & 0.81 \\
\hline $\mathrm{Zn}+\mathrm{ALA}$ & & $6.5 \pm 0.3$ & $6.5 \pm 0.3$ & $6.6 \pm 0.3$ & $6.7 \pm 0.3$ & $0.2 \pm 0.1$ & 0.10 \\
\hline placebo & & $6.6 \pm 0.3$ & $6.7 \pm 0.3$ & $6.6 \pm 0.3$ & $6.6 \pm 0.3$ & $0.0 \pm 0.1$ & 0.94 \\
\hline Insulin (pmol/L) & 0.43 & - & - & - & - & - & - \\
\hline $\mathrm{Zn}$ & & $67 \pm 10$ & $68 \pm 11$ & $66 \pm 10$ & $74 \pm 11$ & $7.7 \pm 6.2$ & 0.24 \\
\hline ALA & & $65 \pm 11$ & $61 \pm 12$ & $68 \pm 11$ & $67 \pm 13$ & $2.4 \pm 8.3$ & 0.78 \\
\hline $\mathrm{Zn}+\mathrm{ALA}$ & & $59 \pm 11$ & $57 \pm 12$ & $57 \pm 11$ & $65 \pm 12$ & $5.8 \pm 9.1$ & 0.54 \\
\hline placebo & & $85 \pm 11$ & $86 \pm 12$ & $80 \pm 11$ & $71 \pm 13$ & $-14.2 \pm 5.6$ & 0.032 \\
\hline HOMA-IR & 0.21 & - & - & - & - & - & - \\
\hline $\mathrm{Zn}$ & & $3.4 \pm 0.6$ & $3.7 \pm 0.7$ & $3.5 \pm 0.6$ & $3.7 \pm 0.6$ & $0.3 \pm 0.4$ & 0.52 \\
\hline ALA & & $3.4 \pm 0.7$ & $3.1 \pm 0.8$ & $3.4 \pm 0.6$ & $3.5 \pm 0.7$ & $0.1 \pm 0.5$ & 0.80 \\
\hline $\mathrm{Zn+ALA}$ & & $2.9 \pm 0.6$ & $3.1 \pm 0.7$ & $3.0 \pm 0.6$ & $3.4 \pm 0.6$ & $0.5 \pm 0.4$ & 0.28 \\
\hline placebo & & $4.5 \pm 0.7$ & $4.8 \pm 0.8$ & $4.0 \pm 0.6$ & $3.5 \pm 0.7$ & $-0.9 \pm 0.4$ & 0.049 \\
\hline Total cholesterol (mmol/L) & 0.86 & - & - & - & - & - & - \\
\hline $\mathrm{Zn}$ & & $4.0 \pm 0.3$ & $4.1 \pm 0.3$ & $4.1 \pm 0.3$ & $4.0 \pm 0.3$ & $0.0 \pm 0.1$ & 0.85 \\
\hline ALA & & $4.4 \pm 0.3$ & $4.5 \pm 0.3$ & $4.6 \pm 0.3$ & $4.7 \pm 0.3$ & $0.3 \pm 0.3$ & 0.38 \\
\hline $\mathrm{Zn}+\mathrm{ALA}$ & & $4.6 \pm 0.3$ & $4.6 \pm 0.3$ & $4.5 \pm 0.3$ & $4.8 \pm 0.3$ & $0.2 \pm 0.2$ & 0.34 \\
\hline placebo & & $4.5 \pm 0.3$ & $4.7 \pm 0.3$ & $4.6 \pm 0.3$ & $4.6 \pm 0.3$ & $0.0 \pm 0.2$ & 0.86 \\
\hline HDL-cholesterol (mmol/L) & 0.79 & - & - & - & - & - & - \\
\hline $\mathrm{Zn}$ & & $1.6 \pm 0.1$ & $1.5 \pm 0.1$ & $1.5 \pm 0.1$ & $1.5 \pm 0.1$ & $-0.1 \pm 0.04$ & 0.037 \\
\hline ALA & & $1.5 \pm 0.1$ & $1.5 \pm 0.1$ & $1.5 \pm 0.1$ & $1.5 \pm 0.1$ & $0.0 \pm 0.04$ & 0.95 \\
\hline $\mathrm{Zn}+\mathrm{ALA}$ & & $1.5 \pm 0.1$ & $1.5 \pm 0.1$ & $1.5 \pm 0.1$ & $1.5 \pm 0.1$ & $0.0 \pm 0.1$ & 0.72 \\
\hline placebo & & $1.5 \pm 0.1$ & $1.4 \pm 0.1$ & $1.4 \pm 0.1$ & $1.4 \pm 0.1$ & $-0.1 \pm 0.1$ & 0.37 \\
\hline LDL-cholesterol $(\mathrm{mmol} / \mathrm{L})$ & 0.80 & - & - & - & - & - & - \\
\hline $\mathrm{Zn}$ & & $2.0 \pm 0.2$ & $2.0 \pm 0.2$ & $1.9 \pm 0.3$ & $2.0 \pm 0.3$ & $0.0 \pm 0.1$ & 0.82 \\
\hline ALA & & $2.2 \pm 0.3$ & $2.3 \pm 0.3$ & $2.5 \pm 0.3$ & $2.5 \pm 0.3$ & $0.3 \pm 0.3$ & 0.34 \\
\hline $\mathrm{Zn}+\mathrm{ALA}$ & & $2.5 \pm 0.3$ & $2.5 \pm 0.2$ & $2.4 \pm 0.3$ & $2.6 \pm 0.3$ & $0.2 \pm 0.1$ & 0.15 \\
\hline placebo & & $2.4 \pm 0.3$ & $2.6 \pm 0.3$ & $2.5 \pm 0.3$ & $2.5 \pm 0.3$ & $0.1 \pm 0.2$ & 0.57 \\
\hline Triglycerides $(\mathrm{mmol} / \mathrm{L})$ & 0.14 & - & - & - & - & - & - \\
\hline $\mathrm{Zn}$ & & $1.1 \pm 0.2$ & $1.3 \pm 0.2$ & $1.6 \pm 0.2$ & $1.3 \pm 0.2$ & $0.2 \pm 0.1$ & 0.11 \\
\hline ALA & & $1.4 \pm 0.2$ & $1.3 \pm 0.2$ & $1.2 \pm 0.2$ & $1.5 \pm 0.2$ & $0.1 \pm 0.1$ & 0.68 \\
\hline $\mathrm{Zn}+\mathrm{ALA}$ & & $1.3 \pm 0.2$ & $1.4 \pm 0.2$ & $1.4 \pm 0.2$ & $1.3 \pm 0.2$ & $0.0 \pm 0.1$ & 0.68 \\
\hline placebo & & $1.4 \pm 0.2$ & $1.4 \pm 0.2$ & $1.5 \pm 0.2$ & $1.5 \pm 0.2$ & $0.0 \pm 0.1$ & 0.94 \\
\hline TC:HDL & 0.97 & - & - & - & - & - & - \\
\hline $\mathrm{Zn}$ & & $2.7 \pm 0.3$ & $2.8 \pm 0.3$ & $2.9 \pm 0.3$ & $2.8 \pm 0.2$ & $0.1 \pm 0.1$ & 0.043 \\
\hline ALA & & $3.0 \pm 0.3$ & $3.1 \pm 0.3$ & $3.1 \pm 0.3$ & $3.2 \pm 0.3$ & $0.1 \pm 0.2$ & 0.51 \\
\hline $\mathrm{Zn}+\mathrm{ALA}$ & & $3.2 \pm 0.3$ & $3.4 \pm 0.3$ & $3.3 \pm 0.3$ & $3.3 \pm 0.3$ & $0.1 \pm 0.1$ & 0.18 \\
\hline placebo & & $3.2 \pm 0.3$ & $3.5 \pm 0.3$ & $3.3 \pm 0.3$ & $3.3 \pm 0.3$ & $0.1 \pm 0.1$ & 0.33 \\
\hline $\operatorname{Zinc}(\mu \mathrm{mol} / \mathrm{L})$ & 0.056 & - & - & - & - & - & - \\
\hline $\mathrm{Zn}$ & & $13.4 \pm 0.5$ & $15.3 \pm 0.7$ & $15.3 \pm 0.5$ & $16.3 \pm 0.5$ & $2.8 \pm 0.7$ & 0.002 \\
\hline ALA & & $11.7 \pm 0.6$ & $12.3 \pm 0.8$ & $12.3 \pm 0.6$ & $12.8 \pm 0.5$ & $1.1 \pm 0.6$ & 0.10 \\
\hline $\mathrm{Zn}+\mathrm{ALA}$ & & $12.6 \pm 0.6$ & $14.5 \pm 0.8$ & $15.2 \pm 0.6$ & $15.0 \pm 0.5$ & $2.4 \pm 0.8$ & 0.019 \\
\hline placebo & & $13.3 \pm 0.6$ & $12.8 \pm 0.8$ & $12.6 \pm 0.6$ & $13.4 \pm 0.5$ & $0.1 \pm 0.4$ & 0.81 \\
\hline
\end{tabular}

${ }^{a}$ Data are expressed as mean \pm s.e. HbA1c, glycated hemoglobin; HOMA-IR, Homeostasis Model of Assessment - Insulin

Resistance; TC, total cholesterol; HDL-C, high density lipoprotein cholesterol; LDL-C, low density lipoprotein cholesterol.

There were no significant differences in biochemical measures among intervention groups at baseline.

${ }^{b}$ Reference intervals for outcome measures are: glucose, $3.0-7.7 \mathrm{mmol} / \mathrm{L}$; insulin, $10-96 \mathrm{pmol} / \mathrm{L}$; total cholesterol, $\leq 5.2$ $\mathrm{mmol} / \mathrm{L}$; HDL-cholesterol, 1.00 - $2.50 \mathrm{mmol} / \mathrm{L} ; \mathrm{LDL}$-cholesterol, $\leq 3.5 \mathrm{mmol} / \mathrm{L}$; triglycerides, $\leq 2.0 \mathrm{mmol} / \mathrm{L} ; \mathrm{HbA} 1 \mathrm{c}$, $3.5-6.0 \%$.

${ }^{\mathrm{c}}$ Repeated Measures analysis (factor ${ }^{\star}$ group P-value with Greenhouse-Geisser adjustment for asphericity).

${ }^{\mathrm{d}}$ Week 12 minus baseline values.

${ }^{\mathrm{e}} \mathrm{P}$-value for change (t-test within each group).

${ }_{\mathrm{f}}$ Conversion to SI Units: IFCC-HbA1c $(\mathrm{mmol} / \mathrm{mol})=[$ DCCT-HbA1c $(\%)-2.15]$ x 10.929. 

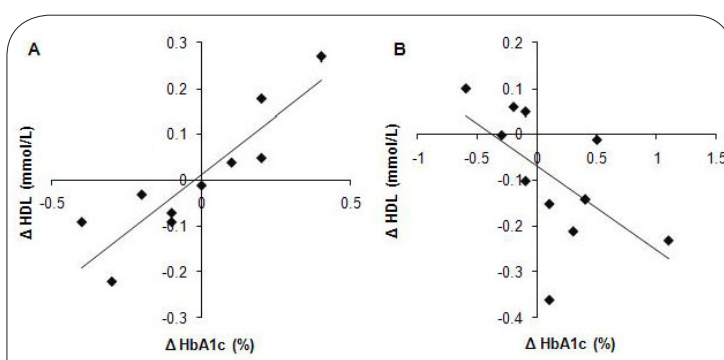

Figure 3. Relationships between the change in HDL cholesterol concentration $(\mathrm{mmol} / \mathrm{L})$ and the change in HbA1c (\%) over 12 weeks (week 12 - baseline values) in the $\mathbf{A}$ ) zinc group and $\mathbf{B}$ ) ALA group. Conversion to SI Units: IFCC-HbA1c $(\mathrm{mmol} / \mathrm{mol})=$ [DCCT-HbA1c (\%) - 2.15] x 10.929.

biochemical markers that differed by treatment group. In particular, the change in HDL concentration over 12 weeks was correlated positively with the change in $\mathrm{HbA1c}$ in the ALA group $(r=0.89, P<0.001, n=10$; Figure $3 \mathrm{~A})$; this relationship was attenuated in the group supplemented with zinc+ALA $(r=0.67, P=0.024 ; n=11)$, and inverse in the $Z n$ group $(r=-0.59$, $P=0.042, n=12$; Figure 3B). Inverse associations were noted in the placebo group between the change in plasma zinc over 12 weeks and the changes in insulin $(r=-0.83, P=0.003$; $n=10)$ and HOMA-IR $(r=-0.75, P=0.012)$.

\section{Discussion}

The present RCT was designed to investigate the effects of zinc, with and without n-3 PUFA supplementation, on markers of lipidemia (total cholesterol, HDL cholesterol, LDL cholesterol, triglycerides) and glycemia (glucose, $\mathrm{HbA1c}$, insulin) in postmenopausal women with T2DM. In particular, we sought to confirm the finding of our previous meta-analysis [8] that zinc supplementation was associated with an increase in $\mathrm{HDL}$ cholesterol concentrations in populations with T2DM.

In the present trial in T2DM, no significant differences were observed between groups in measures of glycemia or lipidemia after zinc and/or ALA supplementation. Participants supplemented with zinc demonstrated a decrease in the $\mathrm{HDL}$ cholesterol concentration and an increase in the TC:HDL ratio at 12 weeks compared to baseline. In contrast to our expectation of an increase in $\mathrm{HDL}$ cholesterol levels in T2DM, the changes in the lipid profile in the present trial are analogous to those observed in the meta-analysis in healthy populations, which exhibited a reduction $(-0.1$ $\mathrm{mmol} / \mathrm{L}$ ) in $\mathrm{HDL}$ cholesterol in response to zinc [8]. The participants in the present study represent a population with medically-controlled T2DM; a normalising effect of medications prescribed in the first-line treatment of T2DM may explain why this group is comparable to healthy subjects in their metabolic responses to zinc.

The effect of zinc supplementation on cholesterol may differ depending on the underlying zinc status of participants. In a Sri Lankan T2DM population with a dietary zinc in take $(3.5 \mathrm{mg} / \mathrm{d})$ below estimated average requirements and plasma zinc concentration $(9.3 \mu \mathrm{mol} / \mathrm{L})$ below the normal range, zinc supplementation significantly increased the plasma zinc concentration $(+12.7 \mu \mathrm{mol} / \mathrm{L})$ and lowered serum total cholesterol [11]. In the present study, no significant change in total cholesterol was observed. The dietary zinc intake $(11.8 \pm 4.2 \mathrm{mg} / \mathrm{d})$ of participants in the present study met the recommended daily intake for women $(8 \mathrm{mg} / \mathrm{d})$ and the plasma zinc concentration $(12.9 \pm$ $2.0 \mu \mathrm{mol} / \mathrm{L}$ ) was within the reference interval. The increase in plasma zinc $(+2.8 \mu \mathrm{mol} / \mathrm{L})$ after zinc supplementation for 12 weeks was comparable to that reported in healthy participants in our meta-analysis $(+2.4 \mu \mathrm{mol} / \mathrm{L})$, supporting the suggestion that supplementation with zinc has effects in medically-controlled T2DM that are similar to its effects in a healthy population.

Associations between the change in HbA1c levels after 12 weeks and the change in the HDL cholesterol concentration were observed in participants supplemented with zinc or ALA, but in different directions. An inverse relationship was seen in the zinc group and a positive relationship in the ALA group, such that a $1 \%$ increase in $\mathrm{HbA1c}$ was associated with a decrease in HDL cholesterol concentration of -0.2 $\mathrm{mmol} / \mathrm{L}$ in the women supplemented with zinc and a 0.5 $\mathrm{mmol} / \mathrm{L}$ increase in participants supplemented with ALA. When zinc and ALA were administered concurrently, the ALA effect was moderated; the increase in HDL was 0.3 $\mathrm{mmol} / \mathrm{L}$ for each $1 \%$ increase in $\mathrm{HbA1c}$ and the relationship was of marginal significance. HDL particles are reported to have properties that are independent of their involvement in cholesterol homeostasis, including the ability to influence insulin sensitivity [38]. Further, HDL cholesterol has been shown to be associated with cardiovascular risk independently of other known risk factors [39]. The association between changes in the concentrations of $\mathrm{HDL}$ cholesterol and $\mathrm{HbA1c}$, which differed according to treatment, warrants further investigation.

The decreases in insulin and insulin resistance (estimated using the HOMA-IR index) observed in the placebo group over the course of the trial were unexpected. The reason for the observed changes is unclear but the potential for a placebo effect should be considered. In a previous trial investigating the effect of $n-3$ PUFA on lipoprotein and glucose metabolism in T2DM, participants supplemented with olive oil $(10 \mathrm{~g} / \mathrm{d})$ as placebo demonstrated decreases in VLDL triglycerides and total cholesterol concentrations. In addition, peripheral insulin sensitivity tended to decrease during n-3 PUFA treatment and to increase during the administration of placebo, with the changes under the two regimes being significantly different [20]. Although the amount of olive oil administered to the placebo group was lower in the present study, the possibility that it conferred favourable effects in T2DM cannot be ruled out.

A number of limitations of the present study may have contributed to the lack of observed differences between 
groups in measures of glycemia or lipidemia after zinc and/or ALA supplementation. In particular the sample size, which was calculated to detect an increase in HDL cholesterol in response to zinc [8], may have been too small to demonstrate differences between groups in biomarkers other than HDL cholesterol. Further, the dose of ALA may not have been large enough to produce measurable effects. Fasting serum insulin can provide valuable data on the relationship of insulin sensitivity to risk factors for T2DM and cardiovascular disease in large epidemiological studies, however its usefulness in other settings has been questioned [40].

\section{Conclusions}

The present RCT did not demonstrate beneficial effects of zinc, with or without ALA supplementation, on glycemia and lipidemia in a population with medically-controlled T2DM, adequate dietary zinc intake, and plasma zinc concentrations within the reference interval. In contrast, the decrease in $\mathrm{HDL}$ cholesterol concentrations observed with zinc supplementation was similar to that reported in healthy populations in our previous meta-analysis [8]. Medications commonly prescribed in the first-line treatment of T2DM may normalise metabolic responses to zinc in a population with adequate zinc intake.

\section{List of abbreviations \\ ALA: $a$-linolenic acid \\ ANOVA: analysis of variance \\ EPA: eicosapentaenoic acid \\ DHA: docosahexaenoic acid \\ HbA1c: glycatedhaemoglobin \\ HDL: high density lipoprotein \\ HOMA: homeostasis model assessment \\ LDL: low density lipoprotein \\ PUFA: polyunsaturated fatty acids \\ T2DM: Type 2 diabetes mellitus \\ TC: total cholesterol}

\section{Competing interests}

The authors declare that they have no competing interests.

\section{Authors' contributions}

MF and SS conceived the study, participated in its design and coordination, data analysis, and drafted the manuscript. MF collected data. IDC provided medical advice and supervision, and commented on drafts of the manuscript. PP performed the statistical analysis and commented on drafts of the manuscript. All authors read and approved the final manuscript.

\section{Acknowledgement and funding}

This study was funded by Sydnovate, The University of Sydney. The funding body did not play any role in designing the study design; or in the collection, analysis, and interpretation of data; in the writing of the manuscript; or in the decision to submit the manuscript for publication.

\section{Publication history}

Received: 15-Nov-2012 Revised: 20-Dec-2012

Accepted: 15-Jan-2013 Published: 24-Jan-2013

\section{References}

1. Wild S, Roglic G, Green A, Sicree R and King H: Global prevalence of diabetes: estimates for the year $\mathbf{2 0 0 0}$ and projections for 2030. Diabetes Care 2004, 27:1047-53. | Article I PubMed

2. Jansen J, Rosenkranz E, Overbeck S, Warmuth S, Mocchegiani E, Giacconi R, Weiskirchen R, Karges W and Rink L: Disturbed zinc homeostasis in diabetic patients by in vitro and in vivo analysis of insulinomimetic activity of zinc. J Nutr Biochem 2012, 23:1458-66. | Article I PubMed

3. Marreiro DN, Geloneze B, Tambascia MA, Lerario AC, Halpern A and Cozzolino SM: Effect of zinc supplementation on serum leptin levels and insulin resistance of obese women. Biol Trace Elem Res 2006, 112:109-18. | Article | PubMed

4. Ramel A, Martinez A, Kiely M, Morais G, Bandarra NM and Thorsdottir I: Beneficial effects of long-chain $n-3$ fatty acids included in an energy-restricted diet on insulin resistance in overweight and obese European young adults. Diabetologia 2008, 51:1261-8. | Article | PubMed

5. De Luis DA, Conde R, Aller R, Izaola O, Gonzalez Sagrado M, Perez Castrillon JL, Duenas A and Romero E: Effect of omega-3 fatty acids on cardiovascular risk factors in patients with type $\mathbf{2}$ diabetes mellitus and hypertriglyceridemia: an open study. Eur Rev Med Pharmacol Sci 2009, 13:51-5. | PDF | PubMed

6. Haffner SM: Dyslipidemia management in adults with diabetes. Diabetes Care 2004, 27 Suppl 1:S68-71. I Article I PubMed

7. Partida-Hernandez G, Arreola F, Fenton B, Cabeza M, Roman-Ramos $\mathrm{R}$ and Revilla-Monsalve MC: Effect of zinc replacement on lipids and lipoproteins in type 2-diabetic patients. Biomed Pharmacother 2006, 60:161-8. | Article | PubMed

8. Foster M, Petocz P and Samman S: Effects of zinc on plasma lipoprotein cholesterol concentrations in humans: a meta-analysis of randomised controlled trials. Atherosclerosis 2010, 210:344-52. | Article I PubMed

9. Zavaroni I, Dall'Aglio E, Alpi O, Bruschi F, Bonora E, Pezzarossa A and Butturini U: Evidence for an independent relationship between plasma insulin and concentration of high density lipoprotein cholesterol and triglyceride. Atherosclerosis 1985, 55:259-66. | Article | PubMed

10. Al-Maroof RA and Al-Sharbatti SS: Serum zinc levels in diabetic patients and effect of zinc supplementation on glycemic control of type 2 diabetics. Saudi Med J 2006, 27:344-50. I PDF I PubMed

11. Gunasekara P, Hettiarachchi M, Liyanage $C$ and Lekamwasam S: Effects of zinc and multimineral vitamin supplementation on glycemic and lipid control in adult diabetes. Diabetes Metab Syndr Obes 2011, 4:53-60. | Article | PubMed Abstract | PubMed Full Text

12. Gupta R, Garg VK, Mathur DK and Goyal RK: Oral zinc therapy in diabetic neuropathy. J Assoc Physicians India 1998, 46:939-42. | Article | PubMed

13. Chausmer AB: Zinc, insulin and diabetes. J Am Coll Nutr 1998, 17:10915. | Article | PubMed

14. Taylor CG: Zinc, the pancreas, and diabetes: insights from rodent studies and future directions. Biometals 2005, 18:305-12. | Article | PubMed

15. Jansen J, Karges $\mathrm{W}$ and Rink L: Zinc and diabetes--clinical links and molecular mechanisms. J Nutr Biochem 2009, 20:399-417. | Article | PubMed

16. Wong CY, Yiu KH, Li SW, Lee S, Tam S, Lau CP and Tse HF: Fish-oil supplement has neutral effects on vascular and metabolic function but improves renal function in patients with Type 2 diabetes mellitus. Diabet Med 2010, 27:54-60. | Article I PubMed

17. Kabir M, Skurnik G, Naour N, Pechtner V, Meugnier E, Rome S, Quignard-Boulange A, Vidal H, Slama G, Clement K, Guerre-Millo M and Rizkalla SW: Treatment for $\mathbf{2}$ mo with $\mathbf{n} \mathbf{3}$ polyunsaturated fatty acids reduces adiposity and some atherogenic factors but does not improve insulin sensitivity in women with type 2 diabetes: a randomized controlled study. Am J Clin Nutr 2007, 86:1670-9. | Article | PubMed

18. Mostad IL, Bjerve KS, Lydersen S and Grill V: Effects of marine n-3 fatty acid supplementation on lipoprotein subclasses measured by nuclear magnetic resonance in subjects with type II diabetes. Eur J Clin Nutr 
Foster et al. Journal of Diabetes Research \& Clinical Metabolism 2013, http://www.hoajonline.com/journals/pdf/2050-0866-2-3.pdf

\section{8, 62:419-29. | Article | PubMed}

19. Stacpoole PW, Alig J, Ammon L and Crockett SE: Dose-response effects of dietary marine oil on carbohydrate and lipid metabolism in normal subjects and patients with hypertriglyceridemia. Metabolism 1989, 38:946-56. | Article | PubMed

20. Vessby B and Boberg M: Dietary supplementation with $\mathbf{n}-\mathbf{3}$ fatty acids may impair glucose homeostasis in patients with non-insulin-dependent diabetes mellitus. J Intern Med 1990, 228:165-71. | Article | PubMed

21. Woodman RJ, Mori TA, Burke V, Puddey IB, Watts GF and Beilin LJ: Effects of purified eicosapentaenoic and docosahexaenoic acids on glycemic control, blood pressure, and serum lipids in type 2 diabetic patients with treated hypertension. Am J Clin Nutr 2002, 76:1007-15. | Article | PubMed

22. Djousse L, Gaziano JM, Buring JE and Lee IM: Dietary omega-3 fatty acids and fish consumption and risk of type 2 diabetes. Am J Clin Nutr 2011, 93:143-50. | Article | PubMed Abstract | PubMed Full Text

23. McManus RM, Jumpson J, Finegood DT, Clandinin MT and Ryan EA: A comparison of the effects of $n-3$ fatty acids from linseed oil and fish oil in well-controlled type II diabetes. Diabetes Care 1996, 19:463-7. | Article | PubMed

24. Egert S, Kannenberg F, Somoza V, Erbersdobler HF and Wahrburg U: Dietary alpha-linolenic acid, EPA, and DHA have differential effects on LDL fatty acid composition but similar effects on serum lipid profiles in normolipidemic humans. J Nutr 2009, 139:861-8. | Article I PubMed

25. Lichten LA and Cousins RJ: Mammalian zinc transporters: nutritional and physiologic regulation. Annu Rev Nutr 2009, 29:153-76. | Article | PubMed

26. National Health and Medical Research Council.Nutrient Reference Values for Australia and New Zealand Including Recommended Dietary Intakes. Canberra: ISBN Print 2006

27. Samman S and Roberts DC: The effect of zinc supplements on plasma zinc and copper levels and the reported symptoms in healthy volunteers. Med J Aust 1987, 146:246-9. | Article | PubMed

28. Tran CD, Miller LV, Krebs NF, Lei S and Hambidge KM: Zinc absorption as a function of the dose of zinc sulfate in aqueous solution. Am J Clin Nutr 2004, 80:1570-3. | Article I PubMed

29. Brown KH, Rivera JA, Bhutta Z, Gibson RS, King JC, Lonnerdal B, Ruel MT, Sandtrom B, Wasantwisut E and Hotz C: International Zinc Nutrition Consultative Group (IZiNCG) technical document \#1. Assessment of the risk of zinc deficiency in populations and options for its control. Food Nutr Bull 2004, 25:S99-203. I Article | PubMed

30. Allain CC, Poon LS, Chan CS, Richmond W and Fu PC: Enzymatic determination of total serum cholesterol. Clin Chem 1974, 20:470-5. | Article | PubMed

31. Sugiuchi H, Uji Y, Okabe H, Irie T, Uekama K, Kayahara N and Miyauchi $\mathrm{K}$ : Direct measurement of high-density lipoprotein cholesterol in serum with polyethylene glycol-modified enzymes and sulfated alpha-cyclodextrin. Clin Chem 1995, 41:717-23. I Article I PubMed

32. Wahlefeld AW, Bergmeyer HU eds: Methods of Enzymatic Analysis. New York: Academic Press Inc 1974.

33. Samman S and Truswell AS: The Friedewald equation for the determination of low-density-lipoprotein cholesterol: a special case. Am J Clin Nutr 1993, 58:928-9. | Article | PubMed

34. Friedewald WT, Levy RI and Fredrickson DS: Estimation of the concentration of low-density lipoprotein cholesterol in plasma, without use of the preparative ultracentrifuge. Clin Chem 1972, 18:499-502. | Article | PubMed

35. Schmidt FH: [Enzymatic determination of glucose and fructose simultaneously]. Klin Wochenschr 1961, 39:1244-7. | Article I PubMed

36. Travis JC: Clinical Radioimmunoassay - State of the Art. Anaheim: Scientific Newsletters, Inc. Radioassay-Ligand Assay, Publishers 1980.

37. Matthews DR, Hosker JP, Rudenski AS, Naylor BA, Treacher DF and Turner RC: Homeostasis model assessment: insulin resistance and beta-cell function from fasting plasma glucose and insulin concentrations in man. Diabetologia 1985, 28:412-9. | Article | PubMed
38. Barter P: HDL-C: role as a risk modifier. Atheroscler Supp/ 2011, 12:267-70. | Article | PubMed

39. Di Angelantonio E, Sarwar N, Perry P et al. Major lipids, apolipoproteins, and risk of vascular disease.JAMA2009; 302: 1993-2000. Article I PubMed

40. Samaras K, McElduff A, Twigg SM, Proietto J, Prins JB, Welborn TA, Zimmet P, Chisholm DJ and Campbell LV: Insulin levels in insulin resistance: phantom of the metabolic opera? Med J Aust 2006, 185:15961. | Article | PubMed

\section{Citation:}

Foster M, Petocz P, Caterson I D and Samman S: Effects of zinc and $\alpha$-linolenic acid supplementation on glycemia and lipidemia in women with type 2 diabetes mellitus: a randomized, double-blind, placebo-controlled trial. Journal of Diabetes Research and Clinical Metabolism 2013, 2:3.

http://dx.doi.org/10.7243/2050-0866-2-3 